\title{
Preconditioning of physiological cyclic stretch inhibits the inflammatory response induced by pathologically mechanical stretch in alveolar epithelial cells
}

\author{
XIANG-ZHI FANG ${ }^{1 *}$, YA-LI GE ${ }^{1 *}$, MIN LI $^{2}$, TIAN-FENG HUANG ${ }^{1}$, ZHANG YANG $^{1}$ and JU GAO ${ }^{1}$ \\ ${ }^{1}$ Department of Anesthesiology, Subei People's Hospital of Jiangsu Province, Yangzhou, Jiangsu 225001; \\ ${ }^{2}$ Department of Anesthesiology, Affiliated People's Hospital of Jiangsu University, Jiangsu 212000, P.R. China
}

Received July 10, 2015; Accepted April 28, 2017

DOI: $10.3892 / \mathrm{etm} .2017 .5611$

\begin{abstract}
The aim of the present study was to investigate the effects of preconditioning of physiological cyclic stretch (CS) on the overexpression of early pro-inflammatory cytokines [including tumor necrosis factor (TNF)- $\alpha$, interleukin (IL)-1 $\beta$ and IL-8] during the inflammatory response induced by pathologically mechanical stretch in lung epithelial cells, and to determine its molecular mechanism of action. Cells were subjected to $5 \% \mathrm{CS}$ for various durations $(0,15,30,60$ and $120 \mathrm{~min}$ ) prior to $6 \mathrm{~h}$ treatment with pathological $20 \%$ CS. In a separate experiment, cells were preconditioned with physiological 5\% CS or incubated with a nuclear factor (NF)- $\kappa B$ inhibitor, pyrroldine dithiocarbamate (PDTC). The expression levels of inflammatory mediators were measured using reverse transcription-quantitative polymerase chain reaction. NF- $\mathrm{KB}$ was quantified using western blot analysis. Preconditioning with physiological 5\% CS for 30, 60 and $120 \mathrm{~min}$ was demonstrated to significantly attenuate the release of pathologically mechanical stretch-induced early pro-inflammatory cytokines (TNF- $\alpha$, IL- $1 \beta$ and IL- 8 ) in alveolar epithelial cells $(\mathrm{P}<0.05)$ and significantly reduce the expression of NF- $\mathrm{kB}(\mathrm{P}<0.05)$. Peak suppression was observed in cells preconditioned for $60 \mathrm{~min}$. In the second set of experiments, it was demonstrated that mechanical stretch-induced release of TNF- $\alpha$, IL-1 $\beta$ and IL- 8 was significantly inhibited by both PDTC pretreatment and 5\% CS pretreatment alone (all $\mathrm{P}<0.05$ ). Furthermore, significant inhibition was also observed when both 5\% CS pretreatment and PDTC pretreatment was used on mechanical stretch-induced cells $(\mathrm{P}<0.05)$, which
\end{abstract}

Correspondence to: Dr Ju Gao, Department of Anesthesiology, Subei People's Hospital of Jiangsu Province, 98 Nan Tong Western Road, Yangzhou, Jiangsu 225001, P.R. China

E-mail: gaoju_003@163.com

${ }^{*}$ Contributed equally

Key words: preconditioning, cyclic stretch, inflammatory response, nuclear factor- $\kappa \mathrm{B}$ was markedly greater than the inhibition induced by either pretreatment alone. The present findings suggest that preconditioning with physiological 5\% CS is able to inhibit the inflammatory response induced by pathologically mechanical stretch in alveolar epithelial cells. These anti-inflammatory effects are induced, at least in part, by suppressing the NF- $\mathrm{KB}$ signaling pathway.

\section{Introduction}

Mechanical ventilation (MV) is typically used for treating patients with acute respiratory failure in intensive care units and is also a crucial element used in general anesthesia (1). However, the misuse of MV may also induce damage known as ventilator-associated lung injury (VALI) (2). It is generally accepted that VALI is an excessive, uncontrolled, inflammatory, response within the lung (3). Previous studies have suggested that the release of pro-inflammatory cytokines have a central role in VALI $(4,5)$. Nuclear factor (NF)- $\mathrm{B}$ is required for maximal transcription of various cytokines, including tumor necrosis factor (TNF)- $\alpha$, interleukin (IL)-8, and IL-1 $\beta(6,7)$. Furthermore, it has been suggested that inhibitors of NF- $\mathrm{kB}$ function may be useful as anti-inflammatory agents (8).

Wolfson et al (9) have recently demonstrated that pathological $18 \%$ cyclic stretch (CS) increased expression of the late pro-inflammatory cytokine high mobility group box protein 1 (HMGB1), whereas physiological cyclic stretch (5\% CS) attenuated oxidative- and lipopolysaccharide-induced increases in HMGB1 expression via a signaling pathway with critical involvement of the transcription factor, signal transducer and activator of transcription 3 (STAT3). A recent study by the present authors demonstrated that preconditioning with physiological cyclic stretch has beneficial effects on mechanical stretch-induced alveolar epithelial cell apoptosis and barrier dysfunction via regulation of Rac and Rho activities (10). Furthermore, another recent study by the present authors demonstrated that preconditioning with physiological 5\% CS is able to reduce the expression of HMGB1 induced by pathologically mechanical stretch through the IL-6/STAT3 pathway associated with upregulated suppressor of cytokine signaling 3 expression (11). However, to the best 
of our knowledge, few studies have assessed the effects of preconditioning with physiological cyclic stretch on early pro-inflammatory cytokines, including TNF- $\alpha$, IL- $1 \beta$ and IL-8, induced by pathologically mechanical stretch in lung epithelial cells. Therefore, it was hypothesized that preconditioning with physiological CS may attenuate TNF- $\alpha$, IL-1 $\beta$, and IL-8 expression and release induced by pathologically mechanical stretch.

A549 cells have been characterized as a typical alveolar epithelial cell line with many features specialized for alveolar epithelial cells and therefore may be considered as an ideal culture model for alveolar epithelial cell type II in research. The present study aims to investigate the preconditioning effects of physiological CS on pathologically mechanical stretch-induced increases in TNF- $\alpha$, IL- $1 \beta$ and IL- 8 expression by using human alveolar epithelial cell line A549, and to elucidate the mechanisms of these effects.

\section{Materials and methods}

Cell culture. The A549 human type II-like alveolar epithelial cell line was obtained from the cellular immunity laboratory of the Medical College of Yangzhou University (Yangzhou, China). A549 cells were cultured in Dulbecco's Modified Eagle's Medium-Ham's F12 medium (HyClone; GE Healthcare Life Sciences, Logan, UT, USA) supplemented with $10 \%$ fetal bovine serum (Gibco; Thermo Fisher Scientific, Inc., Waltham, MA, USA) and 1\% penicillin/streptomycin (Gibco; Thermo Fisher Scientific, Inc.) in a humidified cell incubator in an atmosphere of $5 \% \mathrm{CO}_{2}$ at $37^{\circ} \mathrm{C}$.

Cell deformation. Cells were stretched using a Flexercell Tension Plus FX-4000T system (Flexcell International Corp., Burlington, NC, USA) equipped with a loading station, according to the manufacturer's protocol. These deformations were selected as previously described (12). Cells were seeded at $2.0 \times 10^{5}$ cells $/ \mathrm{cm}^{2}$ on type I collagen-coated flexible bottom BioFlex plates (Flexcell International Corp.) and were then subjected to various different regimens. Initially, to examine the potential protective effects of $5 \% \mathrm{CS}$ and define the optimum preconditioning time for $5 \% \mathrm{CS}$, cells were subjected to CS of 5\% elongation for various durations $(0,15,30,60$ and $120 \mathrm{~min})$ at a frequency of 15 cycles $/ \mathrm{min}$. Cells were subsequently exposed to CS of a higher magnitude (20\% elongation) with the same frequency for $6 \mathrm{~h}$. The sham group consisted of $2.0 \times 10^{5}$ cells $/ \mathrm{cm}^{2}$ and did not receive any treatment. In a second set of experiments, cells were incubated with $100 \mu \mathrm{M}$ pyrroldine dithiocarbamate (PDTC) for $1 \mathrm{~h}$ at $37^{\circ} \mathrm{C}$, which is a specific NF- $\mathrm{B}$ inhibitor, or preconditioned with $5 \% \mathrm{CS}$ for $60 \mathrm{~min}$, or were exposed to both stimuli, prior to $6 \mathrm{~h}$ treatment with pathological CS stimulation $(20 \% \mathrm{CS})$. The sham group did not receive any treatment. The dosages of PDTC were determined according to a recent study (13). The duration of 5\% CS preconditioning in the second set of experiments was determined according to the first set of experiments.

Reverse transcription-quantitative polymerase chain reaction. Following exposure to $\mathrm{CS}$, total RNA was extracted using TRIzol ${ }^{\circledR}$ reagent (Invitrogen; Thermo Fisher Scientific,
Inc.) according to the manufacturer's protocol. Reverse transcription was conducted using a Reverse Transcription System (Promega Corporation, Madison, WI, USA) according to the manufacturer's protocol. A total of $2 \mu \mathrm{g}$ RNA was mixed with $1 \mu \mathrm{l}$ stem-loop reverse transcription primers and RNase free $\mathrm{ddH}_{2} \mathrm{O}$ in a total volume of $12 \mu \mathrm{l}$ and incubated at $65^{\circ} \mathrm{C}$ for $5 \mathrm{~min}$ followed by being chilled on ice for $5 \mathrm{~min}$, then mixed with $4 \mu 1$ 5x reaction buffer, $2 \mu \mathrm{l}$ dNTP mixture, $1 \mu \mathrm{l}$ RNase Inhibitor and $1 \mu \mathrm{l} \mathrm{M}-\mathrm{MuLV}$ reverse transcriptase (Promega Corporation) in a final volume of $20 \mu \mathrm{l}$. The reactions were performed at $25^{\circ} \mathrm{C}$ for $5 \mathrm{~min}$, followed by $42^{\circ} \mathrm{C}$ for $60 \mathrm{~min}$ and $70^{\circ} \mathrm{C}$ for $5 \mathrm{~min}$. cDNA were stored at $-80^{\circ} \mathrm{C}$ for subsequent assessments. A TaqMan ${ }^{\circledR}$ Gene Expression assays (Applied Biosystems, Thermo Fisher Scientific, Inc.) and a 7900HT Fast Real-Time PCR system (Thermo Fisher Scientific, Inc.) were used to quantify the mRNA expression levels of TNF- $\alpha$, IL-8 and IL-1 $\beta$, according to the manufacturer's protocol. Primers for TNF- $\alpha$, IL- 8 and IL-1 $\beta$ were designed and synthesized by Shanghai Shenggong Biological Engineering Technology Service Ltd. (Shanghai, China). Primer sequences were as follows: TNF- $\alpha$, forward, 5'-CCTGTGAGGAGGACGAAC-3' and reverse, 3'-AAGTGGTGGTCTTGTTGC-5'; IL-1 $\beta$, forward, 5'-GGAGAATGACCTGAGCAC-3' and reverse, 3'-GACCAGACATCACCAAGC-5'; IL-8, forward, 5'-TCT GCACCCACTTTTTCCTTG-3' and reverse, 3'-AACCTT CCTGCTGCTTCTGA-5'; and $\beta$-actin, forward, 5'-GTGACG TTGACATCCGTAAAGA-3' and reverse, 3'-GCCGGACTC ATCGTACTCC-5'. The amplified expression of TNF- $\alpha$, IL-8 and IL- $1 \beta$ was normalized to $\beta$-actin expression. PCR conditions were as follows: Initial denaturation at $95^{\circ} \mathrm{C}$ for $5 \mathrm{~min}$; 40 cycles of denaturation at $95^{\circ} \mathrm{C}$ for $5 \mathrm{sec}$ and extension at $60^{\circ} \mathrm{C}$ for $30 \mathrm{sec}$; and denaturation at $95^{\circ} \mathrm{C}$ for $15 \mathrm{sec}$, extension at $72^{\circ} \mathrm{C}$ for $10 \mathrm{sec}$, and a final denaturation at $95^{\circ} \mathrm{C}$ and $15 \mathrm{sec}$. The relative expression of TNF- $\alpha$, IL- 8 and IL- $1 \beta$ in the experimental group compared with the control group was calculated using the $2 \Delta \Delta \mathrm{Cq}$ method (14).

Western blotting. Western blotting was performed as previously described (11). In brief, the harvested lung tissue was weighed, homogenized in RIPA Lysis Buffer (cat. no. P0013B; Beyotime Institute of Biotechnology, Haimen, China) and centrifuged at $12,000 \mathrm{x} \mathrm{g}$ and $4^{\circ} \mathrm{C}$ for $15 \mathrm{~min}$. Total protein concentration in lung tissue homogenates was assessed using a BCA protein assay kit (cat. no. P0009; Beyotime Institute of Biotechnology), according to the manufacturer's protocol. Equal amounts $(20 \mu \mathrm{l})$ of protein were separated by $10 \%$ SDS-PAGE and electrotransferred onto polyvinylidene difluoride (PVDF) membranes. Membranes were blocked with $5 \%$ non-fat milk in TBST buffer $(10 \mathrm{mM}$ Tris- $\mathrm{HCl}, \mathrm{pH} \mathrm{7.5,} 150 \mathrm{mM} \mathrm{NaCl}$ and $1.2 \%$ Tween-20) at room temperature for $1 \mathrm{~h}$. Membranes were incubated with the following primary antibodies: Anti-inhibitor

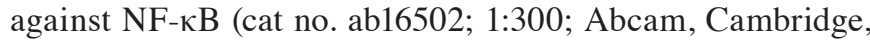
USA), phosphorylated (p)-NF- $\mathrm{B}$ (cat no. 93H1:1:300; Cell Signaling Technology, Inc., Danvers, MA, USA) and anti- $\beta$-actin antibody (cat no. AA128; $1: 500$; Beyotime Institute of Biotechnology) at $4^{\circ} \mathrm{C}$ for $12 \mathrm{~h}$. Subsequently, membranes were incubated at room temperature for $1 \mathrm{~h}$ with the secondary antibody conjugated to horseradish peroxidase (cat. no. A0208; 1:200; Beyotime Institute of Biotechnology). 
A

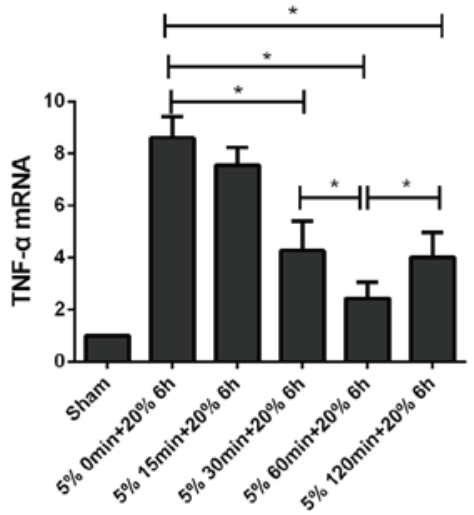

B

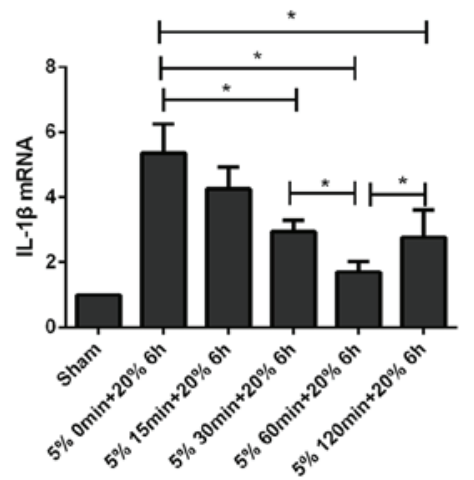

C

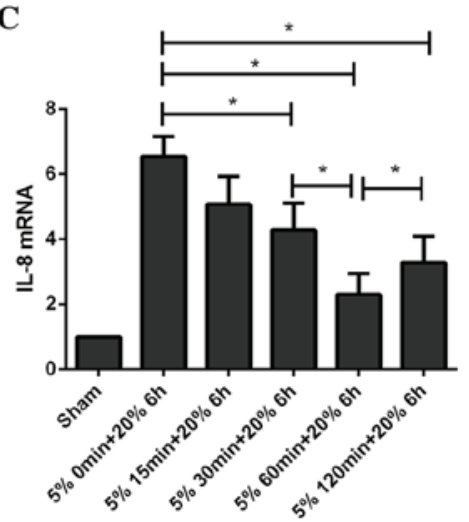

Figure 1. The effect of preconditioning with 5\% CS on the expression of inflammatory mediators in lung epithelial cells prior to pathological $20 \%$ CS. The expression of the inflammatory mediators (A) TNF- $\alpha$, (B) IL-8 and (C) IL-1 $\beta$ mRNA was assessed by reverse transcription-quantitative polymerase chain reaction. Data are expressed as the mean \pm standard deviation from three independent experiments. ${ }^{*} \mathrm{P}<0.05$. CS, cyclic stretch; TNF, tumor necrosis factor; IL, interleukin.

Protein bands were visualized using enhanced chemiluminescence with an ECL Western Blotting System (Bio-Rad Laboratories, Inc., Hercules, CA, USA). The intensity was quantified using Image J 1.8.0 (National Institutes of Health, Bethesda, MD, USA).

Statistical analysis. Data are presented as the mean \pm standard deviation. All experiments were performed a minimum of three times unless otherwise stated. Differences between two groups were tested with unpaired Student's t-test. One-way analysis of variance followed by post hoc analysis with Bonferroni method was applied for multiple-group comparisons. $\mathrm{P}<0.05$ was considered to indicate a statistically significant difference. Data were analyzed using SPSS version 19.0 (IBM Corp., Armonk, NY, USA).

\section{Results}

CS reduces inflammatory mediators in lung epithelial cells. To examine the effect of physiological $5 \% \mathrm{CS}$ on the release of inflammatory mediators, TNF- $\alpha$, IL- $1 \beta$ and IL- 8 levels were quantified by RT-qPCR (Fig. 1). Preconditioning with physiological 5\% CS for 30, 60 and 120 min significantly inhibited TNF- $\alpha$, IL-1 $\beta$ and IL- 8 release (all $\mathrm{P}<0.05$ ). Furthermore, the greatest suppression was observed in cells preconditioned at $5 \% \mathrm{CS}$ for $60 \mathrm{~min}$.

$C S$ reduces $N F-\kappa B$ activation in lung epithelial cells. NF- $\kappa \mathrm{B}$ activation was analyzed via western blotting to investigate the molecular mechanisms responsible for mediating the anti-inflammatory effects of preconditioning with physiological $5 \% \mathrm{CS}$ (Fig. 2). Following exposure to $20 \% \mathrm{CS}$ for $6 \mathrm{~h}, \mathrm{NF}-\kappa \mathrm{B}$ phosphorylation was significantly increased compared with the sham group. Preconditioning with physiological 5\% CS for 30, 60 and 120 min significantly reduced this phosphorylation level (all $\mathrm{P}<0.05$ ). The greatest suppression of NF-kB activation was observed following $5 \% \mathrm{CS}$ stimulation for $60 \mathrm{~min}$.

Comparison of the inhibitory effects of CS and NF- $\kappa B$ signal pathway inhibition on pathologically mechanical stretch-induced inflammatory responses. Following the
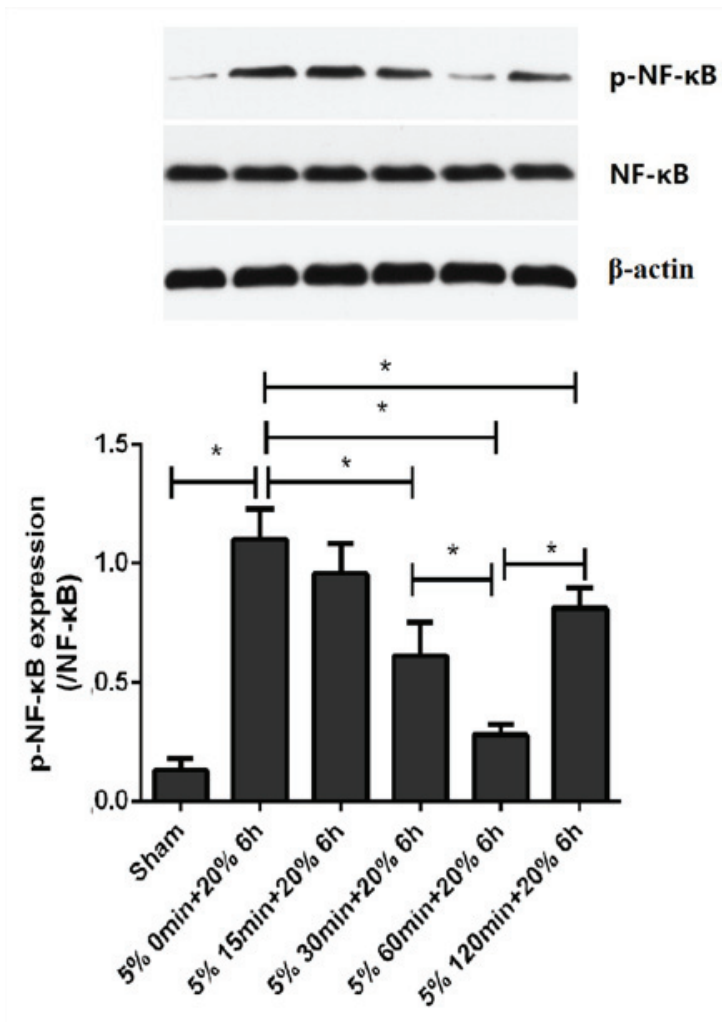

Figure 2. Preconditioning with physiological $5 \%$ CS prior to pathological $20 \%$ $\mathrm{CS}$ may reduce $\mathrm{NF}-\kappa \mathrm{B}$ activation in lung epithelial cells. $\mathrm{NF}-\kappa \mathrm{B}$ activation was assessed by western blotting. Data are expressed as the mean \pm standard deviation from three independent experiments. ${ }^{*} \mathrm{P}<0.05$. CS, cyclic stretch; NF, nuclear factor; $p$, phosphorylated.

observation that CS suppressed both the pathologically mechanical stretch-triggered activations of $\mathrm{NF}-\kappa \mathrm{B}$, the relative contribution of inhibiting these signaling pathways to the anti-inflammatory action of CS was determined. PDTC was used to specifically block NF- $\mathrm{B}$ activity. Cells were exposed to $5 \% \mathrm{CS}, \mathrm{PDTC}$ or PDTC and 5\% CS for $60 \mathrm{~min}$, followed by stimulation with $20 \% \mathrm{CS}$ for $6 \mathrm{~h}$ (Fig. 3). In cells exposed to $20 \% \mathrm{CS}$, it was demonstrated that mechanical stretch-induced release of TNF- $\alpha$, IL-1 $\beta$ and IL- 8 was significantly inhibited 
A

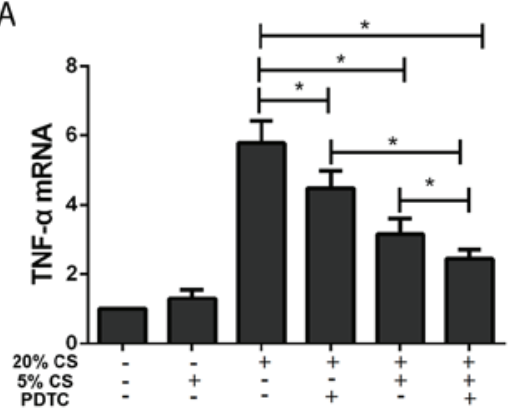

B

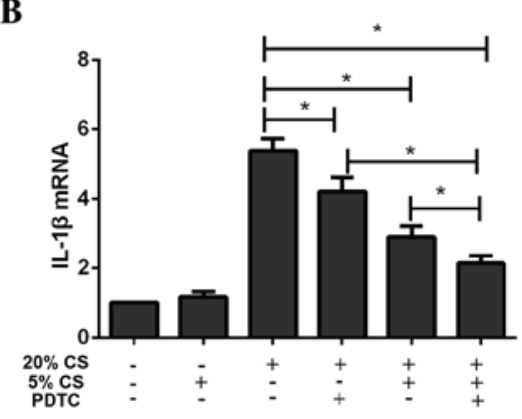

C

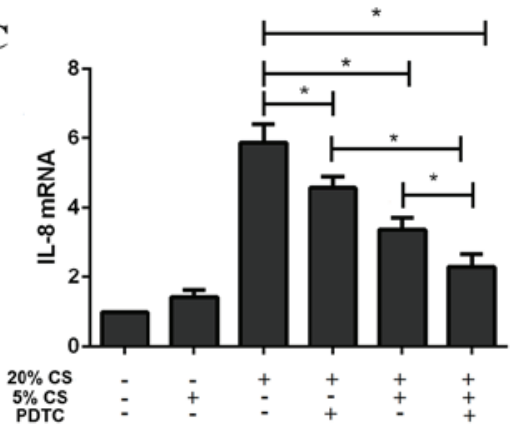

Figure 3. Administration of an $\mathrm{NF}-\kappa \mathrm{B}$ inhibitor suppressed release of pathologically mechanical stretch-induced release of inflammatory mediators in lung epithelial cells. The mRNA expression of the inflammatory mediators (A) TNF- $\alpha$, (B and C) IL- $1 \beta$ and IL- 8 was assessed via reverse transcription-quantitative polymerase chain reaction. Data are expressed as the mean \pm standard deviation from three independent experiments. ${ }^{*}<0.05$. NF, nuclear factor; TNF, tumor necrosis factor; IL, interleukin; CS, cyclic stretch; PDTC, pyrroldine dithiocarbamate.

by both PDTC pretreatment and 5\% CS pretreatment alone (all $\mathrm{P}<0.05)$. Furthermore, significant inhibition was also observed when both 5\% CS pretreatment and PDTC pretreatment were performed to the mechanical stretch-induced cells $(\mathrm{P}<0.05)$, which was markedly greater than the inhibition induced by either pretreatment alone. These results indicate that $\mathrm{NF}-\kappa \mathrm{B}$ activation is associated with the release of inflammatory mediators from A549 cells exposed to $20 \%$ elongation, that the inhibition of $N F-\kappa B$ signal pathways is a mechanism for the anti-inflammatory effects of preconditioning with $5 \% \mathrm{CS}$, and that the effects of $5 \% \mathrm{CS}$ pretreatment may not be completely removed by blocking NF- $\mathrm{B}$ signaling pathway.

\section{Discussion}

The major finding of the present study is that preconditioning with physiological $5 \% \mathrm{CS}$ is able to attenuate the release of the pathologically mechanical stretch induced early pro-inflammatory cytokines TNF- $\alpha$, IL- $1 \beta$ and IL- 8 in alveolar epithelial cells. Furthermore, it was also demonstrated that these anti-inflammatory effects are caused by suppressing the NF- $\mathrm{NB}$ signaling pathways.

Mechanical stretch can have notable effects on alveolar epithelial cell function that alter lung development and induce pathological conditions $(12,15,16)$. It is also known that patients ventilated with high tidal volumes are at risk for VALI and a higher mortality rate $(12,17)$. Although it is unclear precisely how mechanical stretch may induce lung injury, mechanisms that promote the release of inflammatory mediators including TNF- $\alpha$, IL-1 $\beta$, IL- 8 and HMGB 1 been implicated $(8,12,18)$. An administration of drugs with anti-inflammatory features has shown a decrease in VILI $(12,19,20)$.

Serum levels of TNF- $\alpha$, IL- $1 \beta$, IL- 8 peak early during sepsis (21) and pathologic CS is known to upregulate early pro-inflammatory cytokines, including IL-6, IL-1 $\beta$ and IL-8 (18). Pro-inflammatory cytokines that are released early, such as TNF- $\alpha$ and IL- $1 \beta$, may also upregulate the expression of HMGB1, which is a late mediator of sepsis (22). The present results demonstrated that TNF- $\alpha$, IL-1 $\beta$ and IL- 8 were decreased markedly by preconditioning with $5 \% \mathrm{CS}$ administration, suggesting that preconditioning with $5 \% \mathrm{CS}$ provides potential protection from the inflammatory response induced by pathologically mechanical stretch in alveolar epithelial cells. In addition, the peak suppression of inflammatory response was observed in cells preconditioned for $60 \mathrm{~min}$, which was consistent with previous findings by the present authors (10).

It has been suggested that $\mathrm{NF}-\kappa \mathrm{B}$ serves an important role in the regulation of inflammatory response that is the hallmark of VALI (23). Furthermore, mechanical stretching has been demonstrated to induce activation of $\mathrm{NF}-\kappa \mathrm{B}$ in lung fibroblasts and A549 cells $(18,24)$. Activation of the $\mathrm{NF}-\kappa \mathrm{B}$ signaling pathway may be a key mechanism by which excessive stretch results in cellular activation, inflammation, and injury (25). In the present study, the expression of $\mathrm{p}-\mathrm{NF}-\kappa \mathrm{B}$ in cells preconditioned at physiologically relevant amplitude CS (5\% elongation) for 30, 60 and 120 min was determined and revealed obvious reductions. NF- $\kappa \mathrm{B}$ is strongly suggested to be associated with regulating this anti-inflammatory effect. In accordance with these findings, to further clarify the regulatory role of $\mathrm{NF}-\kappa \mathrm{B}$, cells were pre-incubated with an $\mathrm{NF}_{-} \mathrm{\kappa B}$ inhibitor and/or preconditioned with $5 \%$ CS for $60 \mathrm{~min}$ and subsequently stimulated with $20 \% \mathrm{CS}$ for $6 \mathrm{~h}$. The present findings suggest that preconditioning with $5 \% \mathrm{CS}$ significantly inhibited the activation of $\mathrm{NF}-\kappa \mathrm{B}$. Therefore, the present study supports the hypothesis that preconditioning with $5 \% \mathrm{CS}$ inhibits the $\mathrm{NF}-\kappa \mathrm{B}$ signaling pathways and regulates the release of pro-inflammatory cytokines.

In conclusion, it was demonstrated that preconditioning with physiological 5\% CS may attenuate the release of the pathologically mechanical stretch induced early pro-inflammatory cytokines, TNF- $\alpha$, IL- $1 \beta$ and IL- 8 , in alveolar epithelial cells. Furthermore, it was also demonstrated that these anti-inflammatory effects are caused, at least in part by suppressing the $\mathrm{NF}-\kappa \mathrm{B}$ signaling pathway. The present study provides an experimental basis for using preconditioning with MV to reduce ventilator-induced lung injury.

\section{Acknowledgements}

The present study was supported by The National Natural Science Fund (grant nos. 81401626 and 81171838). 


\section{References}

1. Kuchnicka K and Maciejewski D: Ventilator-associated lung injury. Anaesthesiol Intensive Ther 45: 164-170, 2013.

2. Pinhu L, Whitehead T, Evans $\mathrm{T}$ and Griffiths $\mathrm{M}$ : Ventilator-associated lung injury. Lancet 361: 332-340, 2003.

3. Dreyfuss D and Saumon G: Ventilator-induced lung injury: Lessons from experimental studies. Am J Respir Crit Care Med 157: 294-232, 1998.

4. Halbertsma FJ, Vaneker M, Scheffer GJ and van der Hoeven JG: Cytokines and biotrauma in ventilator-induced lung injury: A critical review of the literature. Neth J Med 63: 382-392, 2005

5. Dhanireddy S, Altemeier WA, Matute-Bello G, O'Mahony DS, Glenny RW, Martin TR and Liles WC: Mechanical ventilation induces inflammation, lung injury, and extra-pulmonary organ dysfunction in experimental pneumonia. Lab Invest 86: 790-799, 2006.

6. Yang R, Yang L, Shen X, Cheng W, Zhao B, Ali KH, Qian Z and Ji H: Suppression of NF- $\kappa$ B pathway by crocetin contributes to attenuation of lipopolysaccharide-induced acute lung injury in mice. Eur J Pharmacol 674: 391-396, 2012.

7. Liu F, Sun GQ, Gao HY, Li RS, Soromou LW, Chen N, Deng YH and Feng HH: Angelicin regulates LPS-induced inflammation via inhibiting MAPK/NF- $\kappa$ B pathways. J Surg Res 185: 300-309, 2013.

8. Shu YS, Tao W, Miao QB, Zhu YB and Yang YF: Improvement of ventilation-induced lung injury in a rodent model by inhibition of inhibitory $\kappa$ B kinase. J Trauma Acute Care Surg 76: 1417-1424, 2014.

9. Wolfson RK, Mapes B and Garcia JG: Excessive mechanical stress increases HMGB1 expression in human lung microvascular endothelial cells via STAT3. Microvasc Res 92: $50-55,2014$.

10. Gao J, Huang T, Zhou LJ, Ge YL, Lin SY and Dai Y: Preconditioning effects of physiological cyclic stretch on pathologically mechanical stretch-induced alveolar epithelial cell apoptosis and barrier dysfunction. Biochem Biophys Res Commun 448: 342-348, 2014.

11. Fang XZ, Huang TF, Wang CJ, Ge YL, Lin SY, Zhang Y and Gao J: Preconditioning of physiological cyclic stretch attenuated HMGB1 expression in pathologically mechanical stretch-activated A549 cells and ventilator-induced lung injury rats through inhibition of IL-6/STAT3/SOCS3. Int Immunopharmacol 31: 66-73, 2016.

12. Upadhyay D, Correa-Meyer E, Sznajder JI and Kamp DW: FGF-10 prevents mechanical stretch-induced alveolar epithelial cell DNA damage via MAPK activation. Am J Physiol Lung Cell Mol Physiol 284: L350-L359, 2003.
13. Liu L, Paul A, MacKenzie CJ, Bryant C, Graham A and Plevin R: Nuclear factor kappa B is involved in lipopolysaccharide-stimulated induction of interferon regulatory factor-1 and GAS/GAF DNA-binding in human umbilical vein endothelial cells. Br J Pharmacol 134: 1629-1638, 2001.

14. Livak KJ and Schmittgen TD: Analysis of relative gene expression data using real-time quantitative PCR and the 2(-Delta Delta C(T)) method. Methods 25: 402-408, 2001.

15. Dreyfuss D and Saumon G: Ventilator-induced lung injury: Lessons from experimental studies. Am J Respir Crit Care Med 157: 294-323, 1998.

16. TschumperlinDJ,OswariJ and Margulies AS:Deformation-induced injury of alveolar epithelial cells. Effect of frequency, duration, and amplitude. Am J Respir Crit Care Med 162: 357-362, 2000.

17. Ranieri VM, Suter PM, Tortorella C, De Tullio R, Dayer JM, Brienza A, Bruno F and Slutsky AS: Effect of mechanical ventilation on inflammatory mediators in patients with acute respiratory distress syndrome: A randomized controlled trial. JAMA 282: 54-61, 1999.

18. Iwaki M, Ito S, Morioka M, Iwata S, Numaguchi Y, Ishii M, Kondo M, Kume H, Naruse K, Sokabe M and Hasegawa Y: Mechanical stretch enhances IL-8 production in pulmonary microvascular endothelial cells. Biochem Biophys Res Commun 389: 531-536, 2009.

19. Xia YF, Zhang JH, Xu ZF and Deng XM: Pycnogenol, a compound isolated from the bark of pinus maritime mill, attenuates ventilator-induced lung injury through inhibiting $\mathrm{NF}-\kappa \mathrm{B}-$ mediated inflammatory response. Int J Clin Exp Med 8: 1824-1833, 2015

20. Held HD, BoettcherS, Hamann L and Uhlig S: Ventilation-induced chemokine and cytokine release is associated with activation of nuclear factor-kappaB and is blocked by steroids. Am J Respir Crit Care Med 163: 711-716, 2001

21. Zhang Z, Zhang L, Zhou $\mathrm{C}$ and $\mathrm{Wu} \mathrm{H}$ : Ketamine inhibits LPS-induced HGMB1 release in vitro and in vivo. Int Immunopharmacol 23: 14-26, 2014.

22. Aziz M, Jacob A, Yang WL, Matsuda A and Wang P: Current trends in inflammatory and immunomodulatory mediators in sepsis. J Leukoc Biol 93: 329-342, 2013.

23. Ko YA, Yang MC, Huang HT, Hsu CM and Chen LW: NF-кB activation in myeloid cells mediates ventilator-induced lung injury. Respir Res 14: 69, 2013.

24. Ning Q and Wang X: Role of Rel A and IkappaB of nuclear factor kappaB in the release of interleukin- 8 by cyclic mechanical strain in human alveolar type II epithelial cells A549. Respirology 12: 792-798, 2007.

25. Contreras M, Ansari B, Curley G, Higgins BD, Hassett P, $\mathrm{O}$ Toole D and Laffey JG: Hypercapnic acidosis attenuates ventilation-induced lung injury by a nuclear factor- $\kappa \mathrm{B}$-dependent mechanism. Crit Care Med 40: 2622-2630, 2012 